Published in final edited form as:

J Phys Chem Lett. 2016 October 6; 7(19): 3949-3953. doi:10.1021/acs.jpclett.6b01831.

\title{
UV-induced Adenine Radicals Induced in DNA A-tracts: Spectral and Dynamical Characterization
}

\author{
Akos Banyasz $^{\mathrm{a}}$, Tiia-Maaria Ketola ${ }^{\mathrm{a}, ¥}$, Aurora Muñoz-Losa ${ }^{\mathrm{a}, \dagger}$, Sunny Rishi ${ }^{\mathrm{b}}$, Amitava

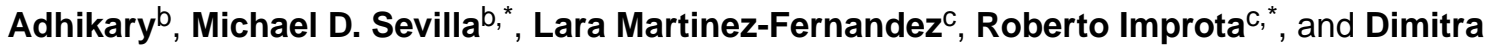 \\ Markovitsi ${ }^{\mathrm{a},{ }^{*}}$ \\ aLIDYL, CEA, CNRS, Université Paris-Saclay, F-91191 Gif-sur-Yvette, France \\ bDepartment of Chemistry, Oakland University, Rochester, MI 48303 \\ 'Istituto Biostrutture e Bioimmagini-Consiglio Nazionale delle Ricerche, Via Mezzocannone 16, \\ I-80134 Napoli, Italy
}

\begin{abstract}
Adenyl radicals generated in DNA single and double strands, $(\mathrm{dA})_{20}$ and $(\mathrm{dA})_{20} \cdot(\mathrm{dT})_{20}$, by oneand two-photon ionization by $266 \mathrm{~nm}$ laser pulses decay at $600 \mathrm{~nm}$ with half-times of $1.0 \pm 0.1$ and $4 \pm 1 \mathrm{~ms}$, respectively. While ionization initially forms the cation radical, the radicals detected for $(\mathrm{dA})_{20}$ are quantitatively identified as N6-deprotonated adenyl radicals by their absorption spectrum, which is computed quantum mechanically employing TD-DFT. Theoretical calculations show that deprotonation of the cation radical induces only weak spectral changes, in line with the spectra of the adenyl radical cation and the deprotonated radical trapped in low temperature glasses.
\end{abstract}

\section{Graphical Abstract}

\footnotetext{
Corresponding Authors. sevilla@oakland.edu, robimp@unina.it, dimitra.markovitsi@cea.fr. ¥present address: CP-Kelco Oy, Kuhnamontie 2, PL 500, FI-44101 Äänekoski, Finland. †present address: Institute of Theoretical Chemistry, University of Vienna, Währinger Str. 17, 1090 Vienna, Austria.

Supporting Information: Details of time-resolved experiments; Additional transient absorption decays; Comparison of literature spectra; Computational details; Additional computational results; Methods for sample preparation for low temperature measurements; Characterization of adenine radicals by ESR spectroscopy.

The authors declare no competing financial interests.
} 


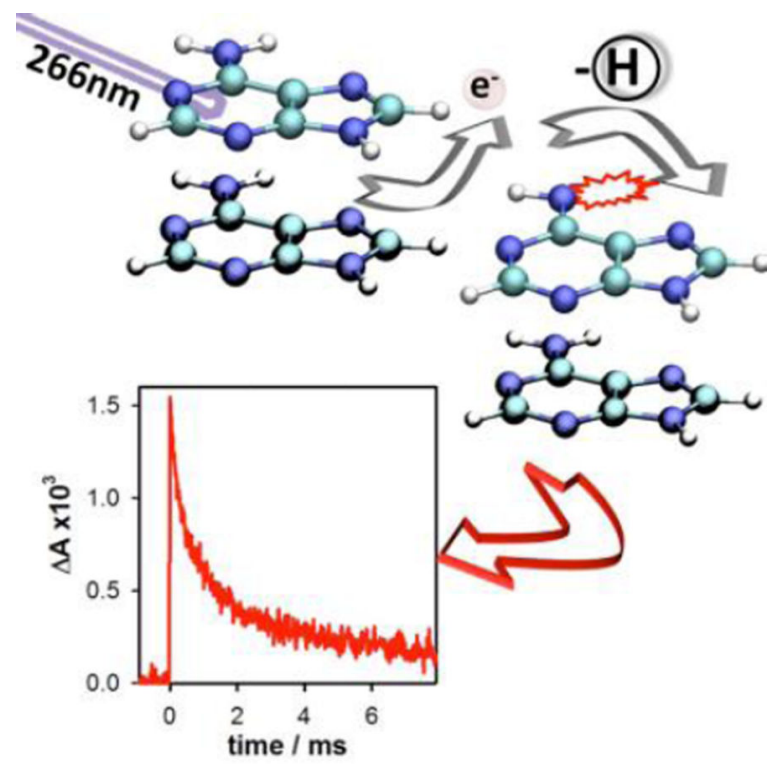

Radicals generated via oxidation of nucleobases have been extensively studied since the 1960s and have elucidated mechanisms of damage to the genetic code by ionizing radiation. ${ }^{1,2}$ The discovery of charge transport in $\mathrm{DNA}^{3}$ has highly contributed to the renewal of this topic. The time evolution of various DNA base radicals has been investigated using pulsed electron beams or lasers. ${ }^{4-12}$ As guanine is known to be a trap for hole transfer, ${ }^{13-14}$ dynamical studies on DNA strands have been focused extensively on guanyl radicals. In contrast, no information is available in the literature about the lifetimes of adenyl radicals, i.e., the adenine cation radical $\left(\mathrm{A}^{\bullet^{+}}\right)$, or its deprotonated neutral aminyl radical form (A-H6)•, either in DNA single strands (ss) or in DNA double strands (ds) to date. Here, we show that such adenyl radicals, generated by $266 \mathrm{~nm}$ laser pulses in the ss-A tract, $(\mathrm{dA})_{20}$, decay on the ms time-scale, and that base pairing prolongs their lifetime.

Furthermore, we present the first characterization of the adenyl radical absorption spectra employing TD-DFT calculations. The computed spectral changes induced by deprotonation of adenine cation radicals are in excellent agreement with those determined in low temperature glasses, for which electron spin resonance (ESR) spectroscopic measurements allow clear identification of the radical species and their protonation states. ${ }^{15}$

The ss and ds DNA oligomers $\left(\mathrm{dA}_{20}\right.$ and $\left(\mathrm{dA}_{20}\right) \bullet\left(\mathrm{dT}_{20}\right)$ (Eurogentec Europe; HPLC purified) were dissolved in phosphate buffer $\left(0.15 \mathrm{~mol} \cdot \mathrm{L}^{-1} \mathrm{NaH}_{2} \mathrm{PO}_{4}, 0.15 \mathrm{~mol} \cdot \mathrm{L}^{-1}\right.$ $\mathrm{Na}_{2} \mathrm{HPO}_{4} ; \mathrm{pH}=7$ ) and were studied at room temperature. As previously reported for various DNA systems, ${ }^{16-17}$ laser excitation at $266 \mathrm{~nm}$ of ss and ds A-tracts leads to electron detachment via one- and two photon ionization. ${ }^{18}$ However, the spectral and dynamical features of the resulting radicals have not been properly studied. An important difficulty arises from the fact that, in addition to the radical species resulting from ionization of Atracts, we also have the formation of adenine ${ }^{19}$ or thymine dimers ${ }^{20}$ which may affect both the spectrum profile and its dynamics. A key point in our time-resolved experiments was the quantification of the various UV-induced species. Thus, at the highest excitation intensity used, $3 \mathrm{MWcm}^{-2}$, the total concentration of the species generated by each laser pulse is 
much lower than the oligomer concentration (SI-Section 1). Another important issue is the photo-ionization of water. ${ }^{4} 6$ Under our experimental conditions, no hydrated electron was detected for the aqueous solvent alone (Figure 1a). Therefore, reactions between the studied oligomers and the ejected electrons $\left(\mathrm{e}^{-}\right)$or the hydroxyl radicals $(\bullet \mathrm{OH})$, generated via twophoton ionization of water, encountered in experiments employing shorter wavelength ${ }^{6}$ and/or higher intensity ${ }^{4}$ excitation pulses are minimized in the present study.

The decay of the hydrated electron was detected at $700 \mathrm{~nm}$ with a time-resolution of $30 \mathrm{~ns}$, which is at least one order of magnitude faster than that used in previous flash photolysis studies on adenyl radicals. ${ }^{4,} 6,18$ They were fitted with an exponential function $\mathrm{y}=\mathrm{y}_{0}+\mathrm{ae}^{-\mathrm{t} / \tau}$ (Figure 1a), with $\tau=0.4 \mu$ s. Such a short lifetime is due to the reaction of hydrated electrons with phosphate ions. ${ }^{1}$ The concentration of ejected electrons, $\left[\mathrm{e}^{-}\right]$, was determined from the zero-time absorbance $\mathrm{y}_{0}$, associated to a molar absorption coefficient of 22700 molL ${ }^{-1} \mathrm{~cm}^{-1}{ }^{21}$ The dependence of $\left[\mathrm{e}^{-}\right]$on the absorbed photons, [hv], (Figure 1b) was fitted with the function $\left[\mathrm{e}^{-}\right] /[\mathrm{h} \nu]=\phi_{1}+\mathrm{a}[\mathrm{h} \nu]$, where $\phi_{1}$ corresponds to the one-photon ionization quantum yield and $a$ is associated with the two photon ionization quantum yield, $\phi_{2}=a[h \nu]$. The $\phi_{1}$ values determined for the single-strand $(\mathrm{dA})_{20},(1.0 \pm 0.1) \times 10^{-3}$, and the double-strand $\mathrm{dA})_{20} \cdot(\mathrm{dT})_{20},(1.1 \pm 0.3) \times 10^{-3}$, are quite similar. While $\phi_{2}$ values vary with excitation intensity, they are proportional to the slope $a$ of the fitted curve and differ for the ss and ds oligomers. We find that $a$ is nearly twice as high for the ss oligomer (0.040) compared to the ds oligomer (0.023). As seen in Figure 1b, at higher excitation intensities, two photon $\mathrm{e}^{-}$yields far outweigh single photon $\mathrm{e}^{-}$yields for both systems.

Figure 2a shows the transient absorption spectra recorded for $(\mathrm{dA})_{20}$ at $0.1,1$ and $10 \mathrm{~ms}$. The absorption band peaking at $600 \mathrm{~nm}$ decays within a few ms with a half-life of $1.1 \pm 0.1$ ms (Figure 3a). Its intensity scales with the number of ejected electrons (inset in Figure 2a) confirming that the species absorbing at $600 \mathrm{~nm}$ result from a photo-ionization process. An increase in the ratio of the electrons $\left[\mathrm{e}^{-}\right]_{\mathrm{h} v 1} /\left[\mathrm{e}^{-}\right]_{\mathrm{h} v 2}$ resulting from one- and two-photon ionization from 0.38 to 0.68 does not modify the decay kinetics (SI; Section 2), showing that the radicals stemming from the two types of ionization processes exhibit similar lifetimes. Argon bubbling in the solution to remove air does not induce any noticeable effect neither in the intensity $(<10 \%)$ nor in the shape of the spectra. This result is in agreement with the literature that the adenyl radicals (cation or deprotonated) do not react with molecular oxygen. ${ }^{1}$ It also shows that the fingerprint of superoxide anion radical, produced from the reaction of oxygen with hydrated electrons and absorbing at wavelengths shorter than 300 $\mathrm{nm},{ }^{22,24}$ is not detected in the transient spectra. This is due to the partial quenching of the hydrated electron by the phosphate buffer. ${ }^{1}$ Finally, no noticeable modification of the decays was observed upon replacing the phosphate buffer by a $\mathrm{NaCl}$ solution while keeping the same ionic strength, in order to maintain base stacking.

The $600 \mathrm{~nm}$ band was also detected for $(\mathrm{dA})_{20} \bullet(\mathrm{dT})_{20}$ at $2 \mu \mathrm{s} .{ }^{18}$ Its decay (Figure $3 \mathrm{~b}$ ) is noisier than that of $(\mathrm{dA})_{20}$ obtained for the same excitation intensity because of the lower two-photon ionization yield of the ds (Figure 1b) and its higher photo-sensitivity (SI, Section 1). The ds signal disappears with a half-life of $4.0 \pm 1.0 \mathrm{~ms}$, revealing that base-pairing of Atracts increases the lifetime of this transient species by about a factor of four. 
The UV part of the spectra in Figure 2a exhibits a more complex time-evolution compared to the visible part. This is due to the contribution of the azetidine intermediate, which is created from a singlet excited state and leads to the formation of adenine dimers at times longer than 0.1 sec. ${ }^{19}$ Based on this knowledge, we subtracted the azetidine spectrum determined at 20 $\mathrm{ms}$, when adenyl radicals have decayed, from the transient spectrum recorded at $0.1 \mathrm{~ms} .{ }^{19}$ The resulting difference spectrum is shown in Figure 2b. The molar absorption coefficient, obtained assuming that the radical concentration at $0.1 \mathrm{~ms}$ equals the concentration of ejected electrons (inset Figure 2a) matches perfectly that determined upon $193 \mathrm{~nm}$ excitation of of $5^{\prime}$-dAMP. ${ }^{6}$ The discrepancy below $300 \mathrm{~nm}$ is due to the higher ground state absorption of oligomer compared to the monomer in this spectral region, affecting the shape of the transient differential spectra (inset in Figure 2b). ${ }^{23}$ Interestingly, a less intense UV band, compared to that of the monomer, was also observed in the adenyl radical spectrum obtained by $193 \mathrm{~nm}$ ionization of an RNA polymer, poly(A) ${ }^{24}$ (Figure SI-2a).

The UV transient absorption of $(\mathrm{dA})_{20} \bullet(\mathrm{dT})_{20}$ also contains dimerization fingerprints. They arise from thymine (6-4) adducts, ${ }^{20}$ whose spectrum peaks at $325 \mathrm{~nm} .{ }^{25-26}$ Their formation from the oxetane intermediate in thymine single strands $(\mathrm{dT})_{20}$ was shown to take place within $4 \mathrm{~ms},{ }^{27}$ a time comparable with the decays of the adenyl radical. For these reasons, and also because of the higher photosensitivity of $(\mathrm{dA})_{20} \cdot(\mathrm{dT})_{20}$ due to the formation of cyclobutane thymine dimers with a high quantum yield $(0.022),{ }^{20}$ refined determination of the radical spectrum at the short wavelength range is delicate and challenging for the duplex.

In Figure $2 \mathrm{~b}$ we notice a very good quantitative agreement between the spectrum of the adenyl radical from (dA) $)_{20}$ and that reported by Candeias and Steenken for (A-H6) • from 5' dAMP. ${ }^{6}$ For both the monomer and the oligomer spectra in Figure $2 b$ the intensity ratio between the high and the low energy bands is 3.4, suggesting that we deal with localized radicals. This is in agreement with already reported $\mathrm{ESR}^{28}$ and TD-DFT studies ${ }^{29}$ which show that deprotonation of $\mathrm{A}^{{ }^{+}}$in stacked monomers or in dinucleoside phosphates leads to localization of the radical site on to a single adenine. A recent pulse radiolysis study on Atracts, reported that hole localization, associated with deprotonation of $\mathrm{A}^{\bullet}$, takes place on the ns time-scale. ${ }^{30}$ Yet, the spectra provided in that study for the deprotonated radical (AH6)• (Figure SI-2b) differ from those shown in Figure 2b. More importantly, the spectrum of UV-induced adenyl cation radical, $\mathrm{A}^{\bullet+}$, the precursor of the deprotonated radical, (A-H6) not available in literature to date. Further, it cannot be determined without the use of additional electron scavengers, ${ }^{1,30}$ which the present study tried to avoid. This knowledge is very important not only for the study of DNA oxidative processes but also for the investigations on hole delocalization processes in A-tracts, which recently has attracted significant interest. ${ }^{3,28,31}$ On this ground, we decided to better characterize the absorption spectra of adenyl radicals.

We computed the absorption spectrum of the cation radical of adenosine $\left(\mathrm{A}^{\bullet}\right)$ and of its deprotonated neutral aminyl radical derivative (A-H6) using PCM/TD-M052X/6-31+G(d,p) calculations in which we explicitly included 5 water molecules of the first solvation shell. This computational approach has been already applied to study the optical properties of dA and A-tracts. ${ }^{19,}$ 23, 32-34 The calculated spectra, red-shifted by $0.55 \mathrm{eV}$ (see SI, Sections 4 and 5 for a more detailed discussion), are in very good agreement with the experimental 
spectra. In particular, the computed spectrum of (A-H6) (Figure 4a) is extremely close to that shown in Figure 2b, providing a broad peak around $620 \mathrm{~nm}$ and another peak at $c a .300$ $\mathrm{nm}$, three times more intense than the former. The spectrum computed for $\mathrm{A}^{\bullet^{+}}$is similar to that of (A-H6)•, but the peak in the UV region is slightly red-shifted with respect to its counterpart of (A-H6) ; it is about four times more intense than the peak in the visible region. At this point we stress that, in contrast to the computed spectra, the experimental ones contain the bleaching of the ground state which leads to a decrease in the intensity and red-shift of the UV band. As shown in the SI, the spectra computed for the A ${ }^{+}$and (A-H6)• in $(\mathrm{dA})_{2}$ dinucleotide are very similar to that shown in Figure $2 \mathrm{~b}$ and $4 \mathrm{a}$, thereby confirming the localization of the radical site.

Though the deprotonation reaction of $\mathrm{A}^{\bullet+}$ is strongly favored in aqueous solution at room temperature, ${ }^{1,6}$ it has been possible to follow it by ESR in low temperature homogeneous aqueous $\left(\mathrm{H}_{2} \mathrm{O}\right.$ or $\left.\mathrm{D}_{2} \mathrm{O}\right)$ glasses $\left(7.5 \mathrm{molL}^{-1} \mathrm{LiCl}\right)^{15,28,35}$ allowing observation of both $\mathrm{A}^{\bullet+}$ and its conjugate base (A-H6) • by ESR spectroscopy. ${ }^{15,28}$ The ESR studies show that in aqueous glasses at $\mathrm{pH} \leq 5, \mathrm{~A} \bullet+$ converts to $(\mathrm{A}-\mathrm{H} 6) \bullet$ either via annealing to higher temperatures (ca. $165 \mathrm{~K})$ or via annealing at lower temperature $(c a .150 \mathrm{~K})$ at higher $\mathrm{pH}(\mathrm{pH}$ ca. 12). Although we observe conversion of $\mathrm{A}^{\bullet+}$ to $(\mathrm{A}-\mathrm{H} 6) \bullet$ at higher annealing temperatures (ca. $165 \mathrm{~K})$, the ESR signal intensity decreases owing to the radical-radical recombination. ${ }^{28}$ As a result, (A-H6)• obtained by this method leads to a poor absorption spectrum of this radical at $77 \mathrm{~K}$, due to its much lower concentration in the sample. On the other hand, samples at a higher $\mathrm{pH}$ (ca. 12) allow for production of (A-H6) at lower temperatures which maintains its signal intensity and results in improved UV-visible spectra of both $\mathrm{A}^{\bullet+}$ and (AH6)•. The detailed procedure for the preparation of the glassy samples and their ESR characterization is given in the SI-Section 6. The ESR spectra of A $\bullet^{+}$and (A-H6)• are quite distinct as the loss of the proton from N6 (A-H6)• leads to a large N6 nitrogen coupling that is apparent in the wings (SI, Section 7). ${ }^{15}$ The UV-visible spectra corresponding to $\mathrm{A} \bullet^{\bullet}$ and (A-H6)• recorded at $77 \mathrm{~K}$ for the same samples as were used for the ESR spectra are shown in Figure $4 \mathrm{~b}$. We observe that the UV-visible spectra of the two radicals are quite similar. Yet, below $330 \mathrm{~nm}$, the spectrum of (A-H6)• is clearly more intense than that of $\mathrm{A}^{\bullet^{+}}$, in agreement with the computational results, showing a blue-shift of the UV band upon deprotonation (Figure 4a).

In conclusion, we have shown that A-tracts undergo one-photon ionization at energies lower by ca. $3.5 \mathrm{eV}$ compared to the adenine ionization potential, ${ }^{36-37}$ generating the equivalent concentration of deprotonated adenyl radicals, which have been characterized by their absorption spectrum. The decays of these radicals determined on the ms time-scale are not governed by the presence of non-biologically relevant species, such alcohols serving as $\bullet \mathrm{OH}$ scavenger, which are used in pulse radiolysis experiments. ${ }^{10}$ The lifetime of (A-H6) radicals increases upon base pairing proving that the helix conformation plays a key role in their reactivity. Our transient spectra have not revealed any fingerprint of species appearing simultaneously with the radical disappearance. This means that the reaction products resulting from the deprotonated radicals absorb below $300 \mathrm{~nm}$. This is the case, for example, of 8-oxo-7,8-dihydro-2'-deoxyadenosine and strand breaks, which have been detected upon high intensity $266 \mathrm{~nm}$ excitation of RNA single stranded poly(A). ${ }^{38}$ We hope that this study will incite determination of the final oxidative products by analytical techniques. Moreover, 
the first spectral characterization of the adenyl radical cation, which is extremely short-lived, will provide the grounds for the interpretation of future time-resolved studies on DNA with high time resolution. Finally, our study does not challenge the deprotonation of adenine cation radicals occurring on the ns time-scale, ${ }^{30}$ rather, our study shows that adenyl radical spectra are more reproducible when obtained by direct UV ionization of DNA than via multistep reactions involving a series of additives.

\section{Supplementary Material}

Refer to Web version on PubMed Central for supplementary material.

\section{Acknowledgments}

Financial support from the French Agency for Research (ANR-10-BLAN-0809-01), the CNRS-CNR PICS project $\left(\mathrm{N}^{\circ}\right.$ 6827-2015)/Bilateral CNR/CNRS and the Legge Regionale 5 Campania 2007 is acknowledged. MDS and AA acknowledge the National Cancer Institute of the National Institutes of Health (Grant RO1CA045424) for support.

\section{REFERENCES}

1. von Sonntag, C. Free-Radical-Induced DNA Damage and Its Repair. Berlin, Heidelberg: SpringerVerlag; 2006.

2. Cadet J, Wagner JR, Shafirovich V, Geacintov NE. One-Electron Oxidation Reactions of Purine and Pyrimidine Bases in Cellular DNA. Int. J. Rad. Biol. 2014; 90:423-432. [PubMed: 24369822]

3. Lewis FD, Wu TF, Zhang YF, Letsinger RL, Greenfield SR, Wasielewski MR. Distance-Dependent Electron Transfer in DNA Hairpins. Science. 1997; 277:673-676. [PubMed: 9235887]

4. Arce R, Rodriguez G, Singmaster K. Intermediates in the Room Temperature Flash Photolysis of Adenine and Some of Its Derivatives. Photochem. Photobiol. 1983; 38:631-637.

5. Deeble DJ, Schuchmann MN, Steenken S, von Sonntag C. Direct Evidence for the Formation of Thymine Radical Cations from the Reaction of $\mathrm{SO}_{4}{ }^{-}$with Thymine Derivatives: A Pulse Radiolysis Study with Optical and Conductance Detection. J. Phys. Chem. 1990; 94:8186-8192.

6. Candeias LP, Steenken S. Ionization of Purine Nucleosides and Nucleotides and Their Components by 193-nm Laser Photolysis in Aqueous Solution: Model Studies for Oxidative Damage of DNA. J. Am. Chem. Soc. 1992; 114:699-704.

7. Melvin T, Cunniffe S, Papworth D, Roldan-Arjona T, Oneill P. Irradiation of DNA with $193 \mathrm{~nm}$ Light Yields Formamidopyrimidine-DNA Glycosylase (Fpg) Protein-Sensitive Lesions. Photochem. Photobiol. 1997; 65:660-665. [PubMed: 9114741]

8. Kobayashi K, Tagawa S. Direct Observation of Guanine Radical Cation Deprotonation in Duplex DNA Using Pulse Radiolysis. J. Am. Chem. Soc. 2003; 125:10213-10218. [PubMed: 12926943]

9. Yamagami R, Kobayashi K, Tagawa S. Dynamics of the Delocalized Charges of a Radical Anion in A•T DNA Duplexes. Chem. Eur. J. 2009; 15:12201-12203. [PubMed: 19834944]

10. Ito T, Kuno S, Uchida T, Fujita S, Nishimoto S. Properties and Reactivity of the Adenosine Radical Generated by Radiation-Induced Oxidation in Aqueous Solution. J. Phys. Chem. B. 2009; 113:389-394. [PubMed: 19072618]

11. Rokhlenko Y, Cadet J, Geacintov NE, Shafirovich V. Mechanistic Aspects of Hydration of Guanine Radical Cations in DNA. J. Am. Chem. Soc. 2014; 136:5956-5962. [PubMed: 24689701]

12. Wu LD, Liu KH, Jie JL, Song D, Su HM. Direct Observation of Guanine Radical Cation Deprotonation in G-Quadruplex DNA. J. Am. Chem. Soc. 2015; 137:259-266. [PubMed: 25506785]

13. Saito I, Nakamura T, Nakatani K, Yoshioka Y, Yamaguchi K, Sugiyama H. Mapping of the Hot Spots for DNA Damage by One-Electron Oxidation: Efficacy of GG Doublets and GGG Triplets as a Trap in Long-Range Hole Migration. J. Am. Chem. Soc. 1998; 120:12686-12687. 
14. Kanvah S, Joseph J, Schuster GB, Barnett RN, Cleveland CL, Landman U. Oxidation of DNA: Damage to Nucleobases. Acc. Chem. Res. 2010; 43:280-287. [PubMed: 19938827]

15. Adhikary A, Khanduri D, Kumar A, Sevilla MD. Photoexcitation of Adenine Cation Radical [A $\bullet^{+}$] in the near UV-Vis Region Produces Sugar Radicals in Adenosine and in Its Nucleotides. J. Phys. Chem. B. 2008; 112:15844-15855. [PubMed: 19367991]

16. Crespo-Hernandez CE, Arce R. Near Threshhold Photo-Oxidation of Dinucleotides Containing Purines Upon 266 Nm Nanosecond Laser Excitation. The Role of Base Stacking, Conformation and Sequence. J. Phys. Chem. B. 2003; 107:1062-1070.

17. Gabelica V, Rosu F, Tabarin T, Kinet C, Antoine R, Broyer M, De Pauw E, Dugourd P. BaseDependent Electron Photodetachment from Negatively Charged DNA Strands Upon $260 \mathrm{~nm}$ Laser Irradiation. J. Am. Chem. Soc. 2007; 129:4706-4713. [PubMed: 17378565]

18. Marguet S, Markovitsi D, Talbot F. One and Two Photon Ionization of DNA Single and Double Helices Studied by Laser Flash Photolysis at 266 nm. J. Phys. Chem. B. 2006; 110:11037-11039. [PubMed: 16771360]

19. Banyasz A, Martinez-Fernandez L, Ketola T, Muñoz-Losa A, Esposito L, Markovitsi D, Improta R. Excited State Pathways Leading to Formation of Adenine Dimers. J. Phys. Chem. Lett. 2016; 7:2020-2023. [PubMed: 27163876]

20. McCullagh M, Lewis F, Markovitsi D, Douki T, Schatz GC. Conformational Control of TT Dimerization in DNA Conjugates. A Molecular Dynamics Study. J. Phys. Chem. B. 2010; 114:5215-5221. [PubMed: 20307059]

21. Hare PM, Price EA, Bartels DM. Hydrated Electron Extinction Coefficient Revisited. J. Phys. Chem. A. 2008; 112:6800-6802. [PubMed: 18610938]

22. Bielski BHJ. Re-Evaluation of Spectral and Kinetic Properties of $\mathrm{HO}_{2} \bullet$ and $\left(\mathrm{O}_{2}{ }^{-}\right)$Free Radicals. Photochemistry and Photobiology. 1978; 28:645-649.

23. Banyasz A, Gustavsson T, Onidas D, Changenet-Barret P, Markovitsi D, Importa R. Multi-Pathway Excited State Relaxation of Adenine Oligomers in Aqueous Solution: A Joint Theoretical and Experimental Study. Chem. Eur. J. 2013; 19:3762-3774. [PubMed: 23335234]

24. Candeias LP, O'Neill P, Jones GDD, Steenken S. Ionization of Polynucleotides and DNA in Aqueous Solution by $193 \mathrm{~nm}$ Pulsed Laser Light: Identification of Base Derived Radicals. Int. J. Radiat. Biol. 1992; 61:15-20. [PubMed: 1345926]

25. Johns HE, Pearson ML, LeBlanc JC, Helleiner CW. The Ultraviolet Photochemistry of Thymidylyl-(3'-5')-Thymidine. J. Mol. Biol. 1964; 9:503-524. [PubMed: 14202282]

26. Blais J, Douki T, Vigny P, Cadet J. Fluorescence Quantum Yield Determination of Pyrymidine (6-4) Pyrimidone Photoadducts. Photochem. Photobiol. 1994; 59:402-404. [PubMed: 8022882]

27. Marguet S, Markovitsi D. Time-Resolved Study of Thymine Dimer Formation. J. Am. Chem. Soc. 2005; 127:5780-5781. [PubMed: 15839663]

28. Adhikary A, Kumar A, Khanduri D, Sevilla MD. The Effect of Base Stacking on the Acid-Base Properties of the Adenine Cation Radical $\left[\mathrm{A}^{\bullet}{ }^{+}\right]$in Solution: ESR and DFT Studies. J. Am. Chem. Soc. 2008; 130:10282-10292. [PubMed: 18611019]

29. Kumar A, Sevilla MD. Photoexcitation of Dinucleoside Radical Cations: A Time-Dependent Density Functional Study. J. Phys. Chem. B. 2006; 110:24181-24188. [PubMed: 17125390]

30. Kobayashi K. Evidence of Formation of Adenine Dimer Cation Radical in DNA: The Importance of Adenine Base Stacking. J. Phys. Chem. B. 2010; 114:5600-5604. [PubMed: 20369809]

31. Harris MA, Mishra AK, Young RM, Brown KE, Wasielewski MR, Lewis FD. Direct Observation of the Hole Carriers in DNA Photoinduced Charge Transport. J. Am. Chem. Soc. 2016; 138:54915494. [PubMed: 27082662]

32. Improta R, Barone V. Interplay between "Neutral" and "Charge-Transfer" Excimers Rules the Excited State Decay in Adenine-Rich Polynucleotides. Angew. Chem. Int. Ed. 2011; 50:1201612019.

33. Gustavsson T, Sarkar N, Vayá I, Jiménez C, Markovitsi D, Importa R. A Joint Experimental/ Theoretical Study of the Ultrafast Excited State Deactivation of Deoxyadenosine and 9Methyladenine in Water and Acetonitrile, Photochem. Photobiol. Sci. Photochem. Photobiol. Sci. 2013; 12:1375-1386. [PubMed: 23615844] 
34. Improta R, Santoro F, Blancafort L. Quantum Mechanical Studies on the Photophysics and the Photochemistry of Nucleic Acids and Nucleobases. Chem. Rev. 2016; 116:3540-3593. [PubMed: 26928320]

35. Adhikary A, Kumar A, Munafo SA, Khanduri D, Sevilla MD. Prototropic Equilibria in DNA Containing One-Electron Oxidized GC: Intra-Duplex Vs. Duplex to Solvent Deprotonation. Phys. Chem. Chem. Phys. 2010; 12:5353-5368. [PubMed: 21491657]

36. Pluharova E, Slavicek P, Jungwirth P. Modeling Photoionization of Aqueous DNA and Its Components. Acc. Chem. Res. 2015; 48:1209-1217. [PubMed: 25738773]

37. Muñoz-Losa A, Markovitsi D, Importa R. A State-Specific PCM-DFT Method to Include Dynamic Solvent Effects in the Calculation of Ionization Energies: Application to DNA Bases. Chem. Phys. Lett. 2015; 634:20-24.

38. Angelov D, Spassky A, Berger M, Cadet J. High-Intensity UV Laser Photolysis of DNA and Purine 2'-Deoxyribonucleosides: Formation of 8-Oxopurine Damage and Oligonucleotide Strand Cleavage as Revealed by HPLC and Gel Electrophoresis Studies. J. Am. Chem. Soc. 1997; 119:11373-11380 

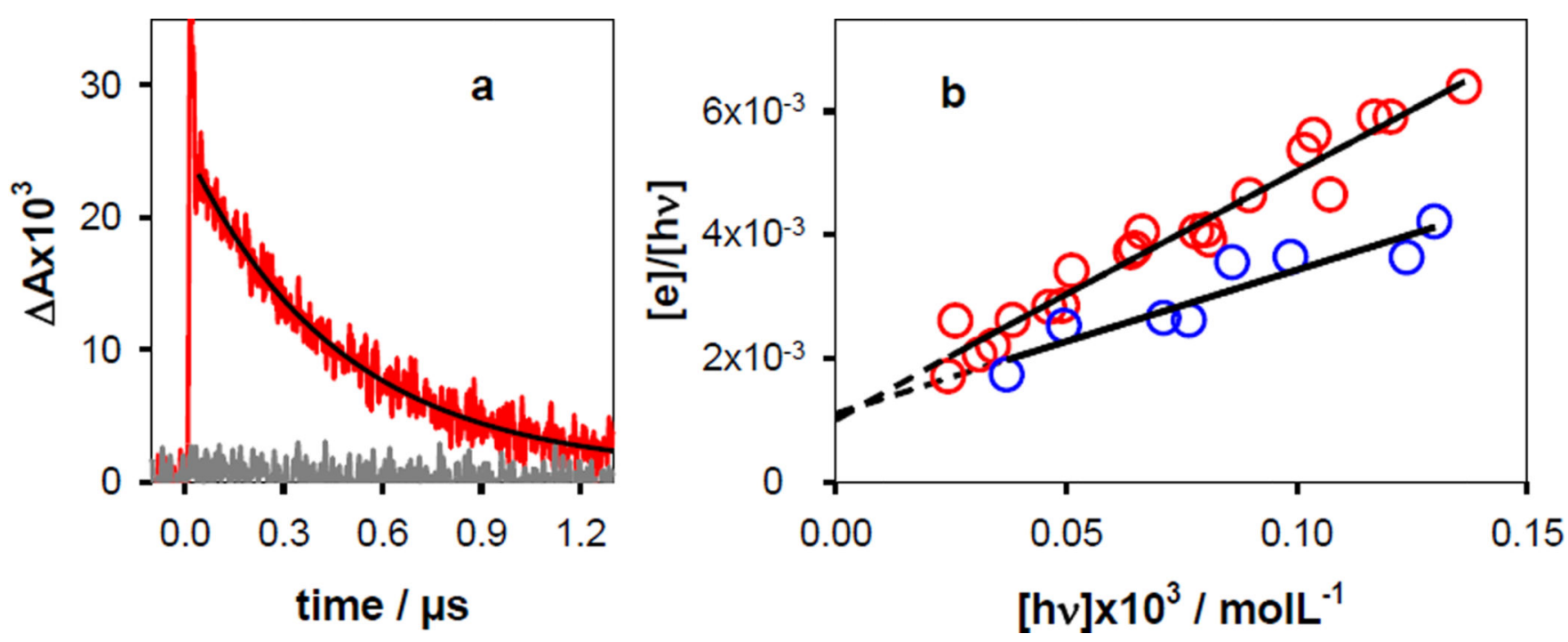

Figure 1.

(a) Transient signals recorded at $700 \mathrm{~nm}$ for the buffer alone (grey) and a deaerated $(\mathrm{dA})_{20}$ solution (red) with an excitation intensity of $3 \mathrm{MWcm}^{-2}$; the dark line corresponds to the fit with the function $y=y_{0}+a e^{-t / \tau},(\tau=0.4 \mu s)$. (b) Electron $\left[\mathrm{e}^{-}\right]$ejected as a function of the photons $\left[\mathrm{h} v\right.$ ] absorbed by $(\mathrm{dA})_{20}$ (red) and $(\mathrm{dA})_{20} \bullet(\mathrm{dT})_{20}$ (blue). Experimental points (circles) are fitted with the function $\left[\mathrm{e}^{-}\right] /[\mathrm{h} \nu]=\phi_{1}+\mathrm{a}[\mathrm{h} \nu]$ (solid lines). 


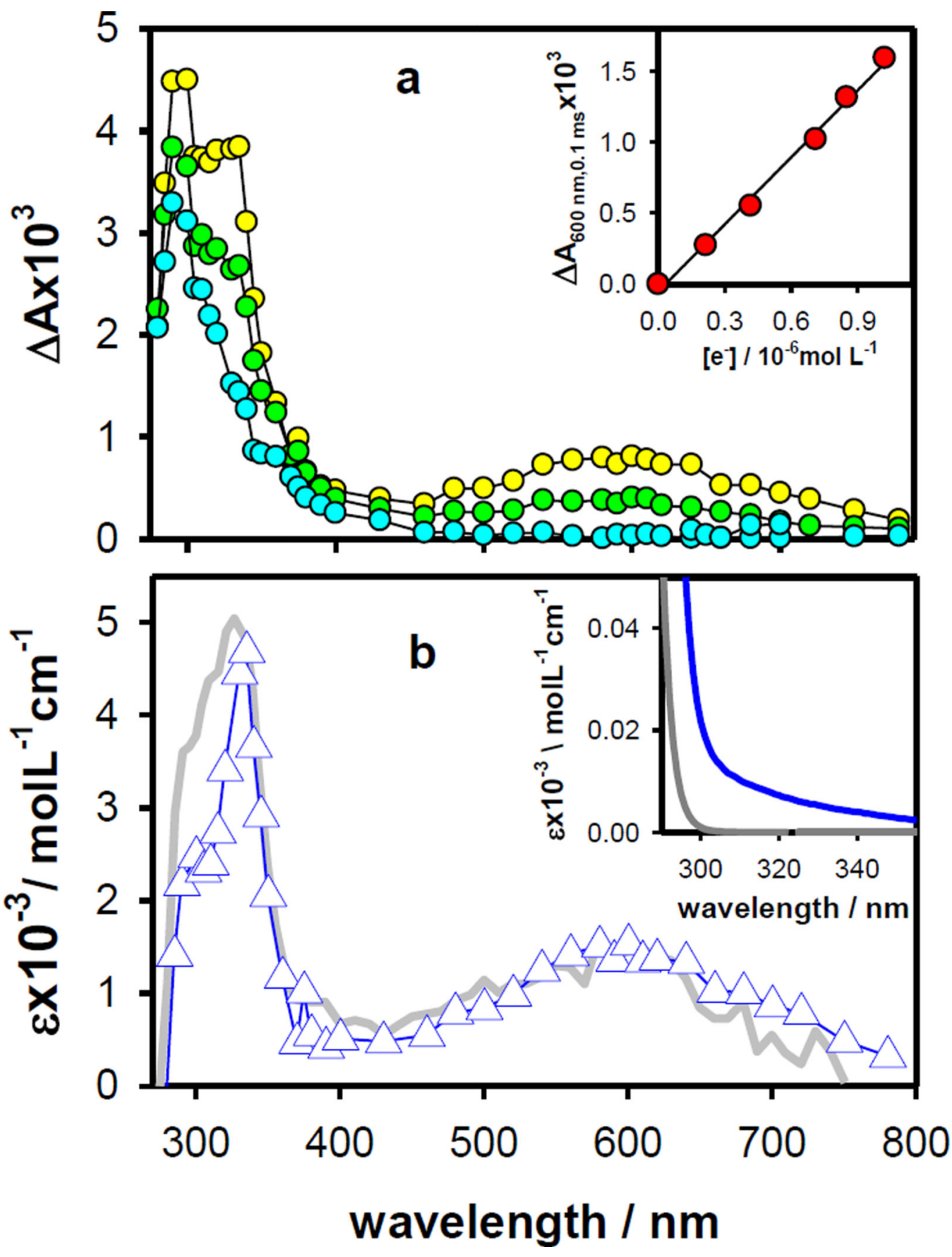

Figure 2.

(a) Transient absorption spectra recorded for the ss oligomer (dA) 20 at $0.1 \mathrm{~ms}$ (yellow), $1 \mathrm{~ms}$ (green) and $10 \mathrm{~ms}$ (cyan). (b) Triangles: difference of the $(\mathrm{dA})_{20}$ spectra recorded at 0.1 and $20 \mathrm{~ms}$, associated with adenine dimerization; ${ }^{19}$ solid line: spectrum obtained upon $193 \mathrm{~nm}$ excitation of $5^{\prime}$-dAMP at $300 \mathrm{~ns} .{ }^{6}$ Inset in (a): Correlation of transient absorbance detected at $600 \mathrm{~nm}$ and $0.1 \mathrm{~ms}$ with the concentration of ejected hydrated electrons. Inset in (b): ground state absorption spectra of $5^{\prime}$-dAMP (grey) and $(\mathrm{dA})_{20}$; the molar absorption coefficient is given per base. ${ }^{23}$ 


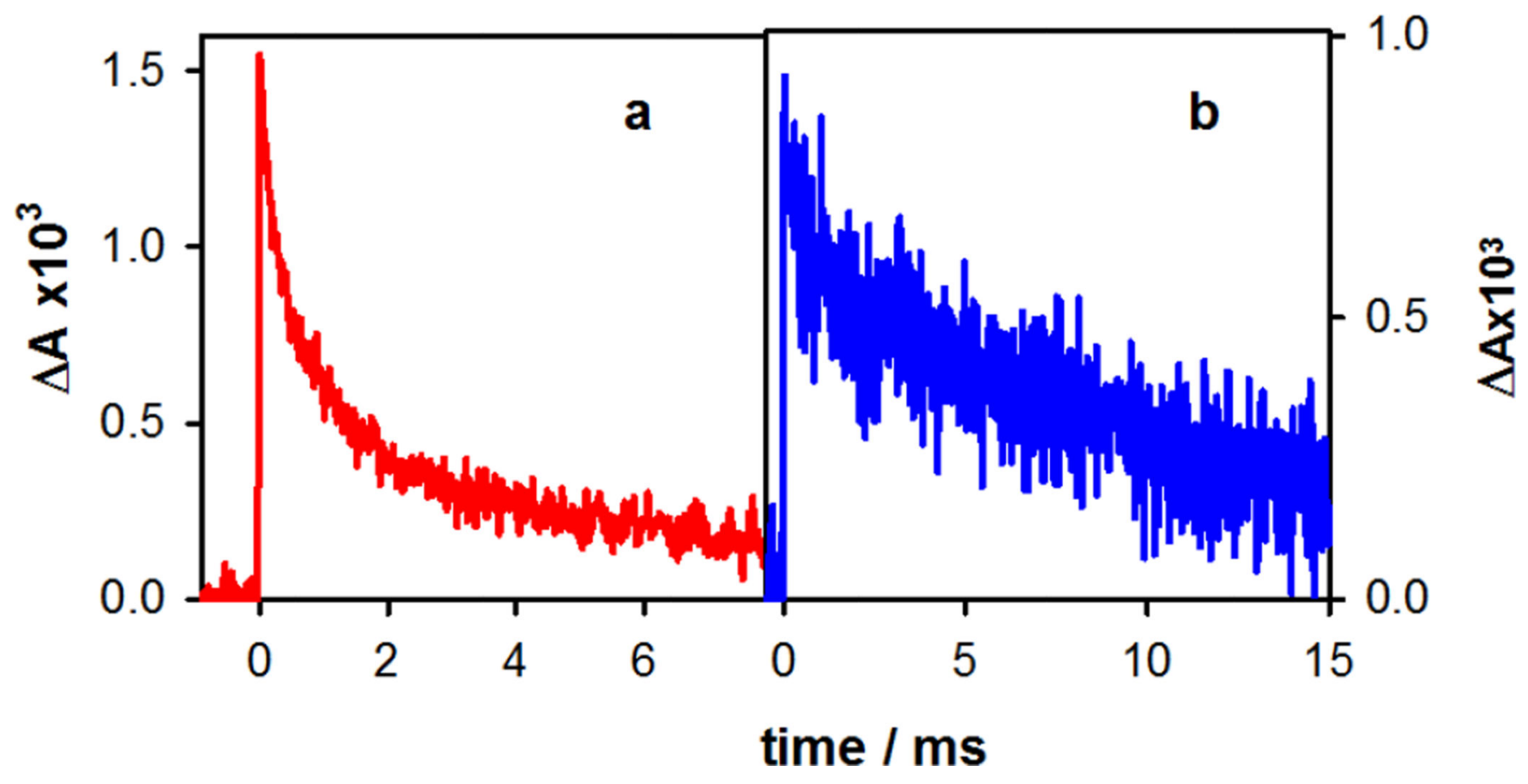

Figure 3.

Transient absorption signals recorded at $600 \mathrm{~nm}$ for $(\mathrm{dA})_{20}(\mathrm{a})$ and $(\mathrm{dA})_{20} \bullet(\mathrm{dT})_{20}$ (b). Excitation intensity: $3 \mathrm{MWcm}^{-2}$. 

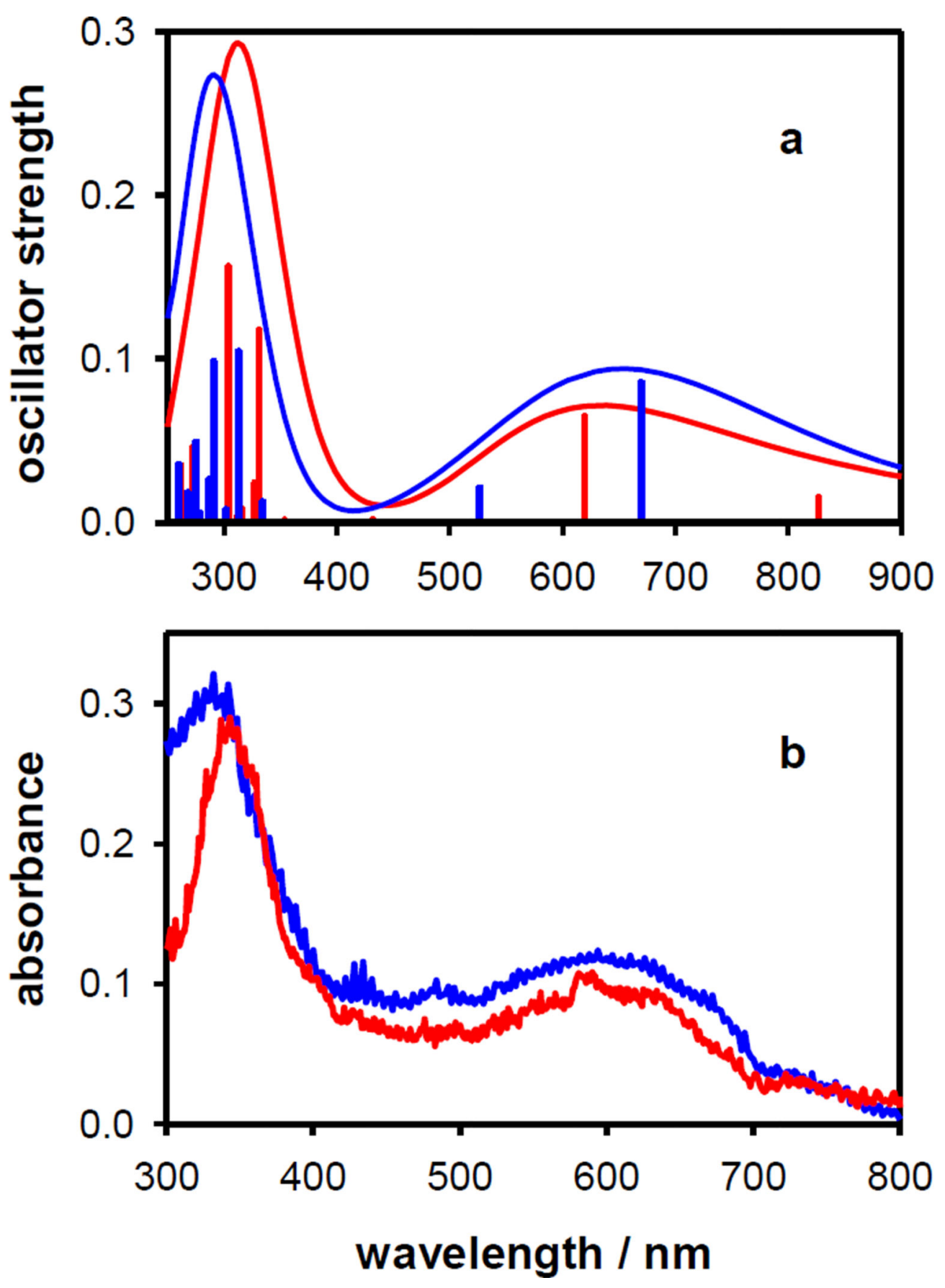

Figure 4.

Electronic absorption spectra determined for the radical cation (red) and the deprotonated radical (blue) of dA. (a) PCM/TD-M052X/6-31+G(d,p)// PCM/M052X/6-31+G(d,p) level including five water molecules. Energies are homogenously decreased by $0.55 \mathrm{eV}$. Spectral shapes were obtained by convoluting each transition by a Gaussian curve with a width of 0.4 eV (FWHM). The electronic transitions are shown as sticks with their oscillator strength. (b) 
UV-visible spectra of A $\bullet^{+}$(red) and its N-6 deprotonated radical, (A-H6)• (blue) at $77 \mathrm{~K}$ produced by $\mathrm{Cl}_{2}{ }^{\bullet}$ - one electron oxidation in a $7.5 \mathrm{molL}^{-1} \mathrm{LiCl}$ aqueous glass. 